\title{
Placental Leucine Aminopeptidase- and Aminopeptidase A-Deficient Mice Offer Insight concerning the Mechanisms Underlying Preterm Labor and Preeclampsia
}

\author{
Shigehiko Mizutani, ${ }^{1}$ John W. Wright, ${ }^{2}$ and Hiroshi Kobayashi ${ }^{3}$ \\ ${ }^{1}$ Daiya Building Lady's Clinic, Meieki 3-15-1, Nakamura, Nagoya 450-0002, Japan \\ ${ }^{2}$ Department of Psychology, Veterinary and Comparative Anatomy, Pharmacology and Physiology, \\ and Programs in Neuroscience and Biotechnology, Washington State University, Pullman, WA 99164-4820, USA \\ ${ }^{3}$ Department of Obstetrics-Gynecology, Nara Medical University, 840 Shijo-cho, Kashihara, Nara 634-8522, Japan \\ Correspondence should be addressed to Hiroshi Kobayashi, hirokoba@naramed-u.ac.jp \\ Received 6 August 2010; Accepted 8 October 2010 \\ Academic Editor: Monica Fedele
}

Copyright ( 2011 Shigehiko Mizutani et al. This is an open access article distributed under the Creative Commons Attribution License, which permits unrestricted use, distribution, and reproduction in any medium, provided the original work is properly cited.

Preeclampsia and preterm delivery are important potential complications in pregnancy and represent the leading causes for maternal and perinatal morbidity and mortality. The mechanisms underlying both diseases remain unknown, thus available treatments (beta2-stimulants and magnesium sulfate) are essentially symptomatic. Both molecules have molecular weights less than $5-8 \mathrm{kDa}$, cross the placental barrier, and thus exert their effects on the fetus. The fetus produces peptides that are highly vasoactive and uterotonic and increase in response to maternal stress and with continued development. Fetal peptides are also small molecules that inevitably leak across into the maternal circulation. Aminopeptidases such as placental leucine aminopeptidase (PLAP) and aminopeptidase A (APA) are large molecules that do not cross the placental barrier. We have shown that APA acts as an antihypertensive agent in the pregnant spontaneously hypertensive rat by degrading vasoactive peptides and as a result returns the animal to a normotensive state. P-LAP also acts as an antiuterotonic agent by degrading uterotonic peptides and thus prolongs gestation in the pregnant mouse. Given the ever increasing worldwide incidences of preeclampsia and preterm labor, it is imperative that new agents be developed to safely prolong gestation. We believe that the use of aminopeptidases hold promise in this regard.

\section{Introduction}

It is well known that the fetus produces bioactive peptides such as angiotensin II (AngII), vasopressin (AVP), and oxytocin (OT), that are highly vasoactive and uterotonic, respectively [1-4]. It is also known that secretions of these peptides from the fetus increase in parallel with fetal growth and in response to stressors such as hypoxia. Since hormones may leak out from the fetoplacental unit because of lowmolecular weight, they are capable of exerting their effects on the mother. Therefore, the existence of a placental barrier against these hormones and/or maternal blood is essential for the homeostasis of pregnancy. The fetoplacental unit is a rapidly growing organ and allows for maternal exposure to fetal hormones by retroplacental maternal blood supply with advancing pregnancy. Thus, fetal peptide hormones are potentially active not only within the fetoplacental unit but also on the maternal side during normal and pathophysiological pregnancy.

Our basic and clinical research has shown that the placental and maternal barriers to the hormonal effects of these fetal peptides are the aminopeptidases: placental leucine aminopeptidase (P-LAP) (EC3.4.11.3) that acts on oxytocin (OT), vasopressin (AVP) [5-7], and aminopeptidase A (APA ) (EC3.4.11.7) that act on AngII, respectively, $[8,9]$ as presented in Figure 1. Our research has shown that placental aminopeptidases are likely involved in both the onset of labor (preterm labor) and preeclampsia via degrading fetoplacental peptides [10]. 


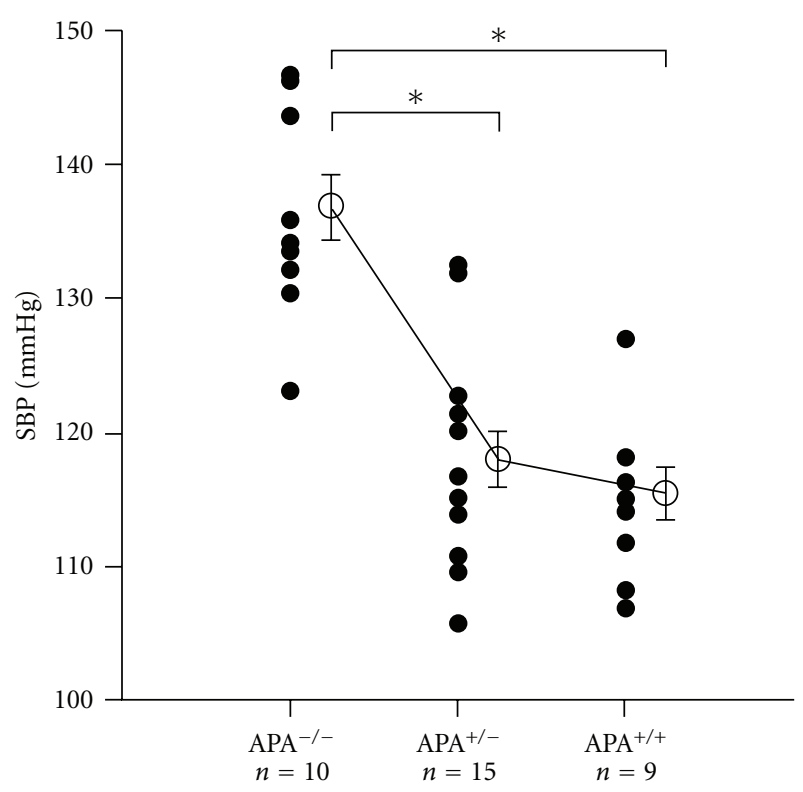

FIGURE 1: Effects of APA deficiency on SBP. Systolic blood pressure (SBP) of $\mathrm{APA}^{-/-}, \mathrm{APA}^{+/-}$, and $\mathrm{APA}^{+/+}$mice at 3 months $(n=9$ to 15 per group) was determined by a tail-cuff system. Each datum point represents the mean measurement of 2-d taken after 4-d training period. The average \pm SEM of each group is represented by an open circle and a bar. ${ }^{*} P<.05$.

This paper begins with a description of adverse reactions that accompany the presently used drugs for preeclampsia (hypertensive disorder in pregnancy) and preterm labor. We also discuss the roles of angiotensinase and oxytocinase in pregnancy and the clinical application of both enzymes. This is followed by a description concerning the importance of the knockout mouse of P-LAP and APA in the understanding of the active roles of both enzymes in vivo. We then discuss the roles of P-LAP and APA as promising agents to treat preeclampsia and preterm labor by degrading bioactive hormones derived from fetoplacental circulation. In addition, our animal experiments have shown that APA is an excellent candidate as an antihypertensive agent in humans.

\section{Adverse Drug Reactions}

Preeclampsia and preterm delivery represent serious complications during pregnancy. Preeclampsia is a hypertensive disorder that occurs during human pregnancy and presents potentially life-threatening consequences for both mother and fetus [11]. It is defined as a sustained elevation in blood pressure (BP; >140/90 mmHg, at two readings separated by 6 hours) accompanied by proteinuria $(>300 \mathrm{mg} / \mathrm{l})$ in a previously normotensive woman. Preeclampsia is estimated to be present in $5-7 \%$ of pregnancies in developed countries and occurs at an even a higher rate in developing countries. At present, the only cure for preeclampsia eclampsia is termination of pregnancy, thus obstetricians are forced to decide upon premature delivery irrespective of gestational week [12]. According to the March of Dimes Organization
(New York, USA), worldwide approximately one million deaths occurred during the first month of life due to preterm birth in 2005 [13].

The causes of both preeclampsia and preterm labor remain unknown, thus present treatments are essentially symptomatic. Conventional antihypertensive medications are not routinely administered to preeclampsia patients since these agents fail to reduce the risk of eclampsia [12]. Beta2 stimulants and magnesium sulfate are used to treat preterm labor; however, both drugs cross the placental barrier and exert their effects on the fetus. In addition, treatment with Beta 2 stimulants presents serious maternal side effects such as arrhythmia, cardiac ischemia, and pulmonary edema, with an increased likelihood of tachycardia in both mother and fetus. Myocardial necrosis in newborns treated with terbutaline has been reported [14]. Cardiovascular deterioration due to long-term Beta2stimulant therapy contributes to the downregulation of fetal beta receptors, thus resulting in impaired cardiac function following birth [15]. Magnesium sulfate is essentially an anticonvulsant, therefore its administration causes little change in BP. Undesirable side effects such as depressed respiration and cardiac arrest frequently occur with increased serum magnesium levels, and this treatment has been associated with increased perinatal mortality among fetuses [16].

Recently, we have found that the administration of preeclampsia doses of magnesium sulfate to pregnant spontaneously hypertensive rats (SHR) was associated with delayed cardiovascular vessel formation, suggesting adverse effects on the fetal heart [17]. It is known that idiopathic dilated cardiomyopathy in children results in a high rate of mortality. Cardiac transplantation is the treatment of choice in those patients who fail to respond to therapeutics [18]. Although various factors have been suggested to cause such myocardial damage, no specific etiology has been identified. Injury to myocardial cells is the initiating factor that leads to cell death. It is likely that in utero exposure to both Beta2 stimulants and magnesium sulfate results in considerable fetal myocardium cell loss. The consequence of this condition is a neonatal myocardium that fails to generate sufficient contractile force to produce adequate cardiac output. Thus, the fetal effects associated with these agents are very problematic regarding longterm prognosis following birth. Given the ever-increasing worldwide incidences of preeclampsia and preterm labor, it is imperative that new agents be developed to safely prolong gestation.

\section{Possible Role of Angiotensinase}

Because AVP and AngII are known to play an important role in normal and aberrant (preeclampsia) fetoplacental circulation, the clearance of these peptides in the placenta is important for both fetus and mother [19]. The levels of AngII in umbilical venous blood was found to be higher than those in umbilical arterial blood in normal pregnancy and preeclampsia, and the levels in both umbilical and maternal venous blood in cases of severe preeclampsia were also much higher than those measured during normal 
pregnancy. The gradient of AngII between umbilical venous and arterial blood suggests the active involvement of placental angiotensin-converting enzyme (ACE) (EC 3.4.15.1) in AngII production in the fetoplacental unit. In addition, data from Broughton-Pipkin and Symonds [1] showed a greater difference between venous and arterial blood in cases of preeclampsia, which suggested an increased AngII release from the stressed or transiently hypoxemic fetus and a decreased degradation by AngII degrading enzyme (angiotensinase) in placenta [8]. Kingdom and colleagues [2] investigated the relation between umbilical arterial oxygen partial pressure and AngII levels in the umbilical vein during human delivery. They found that if the human fetus suffered from a low oxygen level caused by stress, the level of AngII in the umbilical vein was high. This indicates that under stress conditions, the AngII level will go up in the human fetus. We found ACE (kininase II) present in the human placenta [20, 21] and showed that maternal serum ACE activity did not change in preeclampsia compared with normal pregnancy [19].

The renin-angiotensin system (RAS) is recognized as an important contributor to hypertension [22], and the majority of research concerned with this system has focused on the synthesis of AngII and its interaction with angiotensin receptors [23]. Until recently, little attention had been paid to AngII degradation and its relevance as a controlling factor in hypertension $[9,24,25]$. An understanding of the role of APA in the RAS is important given its ability to cleave the N-terminal aspartic acid of AngII, thus forming angiotensin III (AngIII) and acting as a rate-limiting factor in the availability of the potent vasoconstrictor, AngII [26]. The potency of AngIII as a hypertensive agent is approximately 25\% that of AngII making AngII the more important ligand; hence, APA has also been called angiotensinase. Because AngII concentrations in the enormously enlarging local tissue (fetoplacental unit) are determined not only by its synthesis but also by its degradation, the rate of APA-induced degradation of AngII is an important factor as an underlying mechanism of both fetoplacental and maternal BP [19].

\section{Possible Role of Oxytocinase (Vasopressinase)}

The pathophysiology of preterm labor is unknown. This is not surprising since the mechanisms of onset of labor at term remain unknown. Although many disorders such as infections and multiple gestations are associated with preterm labor, the cause of preterm labor in more than 50\% of pregnancy is idiopathic (spontaneous preterm labor). It is known that only idiopathic forms of preterm labor are spontaneous [27]. Spontaneous preterm labor after week 32 is less likely to be complicated by infection [28].

Although the onset of labor is the expression of a constellation of interrelated events, including fetal control, steroid hormone changes, prostaglandin production, and oxytocin action, Liggins et al. [29] have shown that the fetus signals the onset of labor to the mother. They showed that the maturation of the fetal hypothalamic-pituitary-adrenal axis appears to create the signal for a train of events that result in delivery. They suggested that elevated levels of fetal cortisol act on the placenta to cause changes in estrogen and progesterone balance; an increase of estrogen and a decrease of progesterone and then these changes in steroid hormones preceding parturition result in the release of large concentrations of prostaglandin $\mathrm{F}_{2}$ alpha from the maternal placenta (decidua) in the ovine parturition [30].

On the other hand, Chard and colleagues [4] suggested the possible involvement of fetal OT during delivery. They showed that OT and AVP are consistently found in human umbilical arterial and venous plasma at the time of delivery. These levels are higher in the umbilical artery than the umbilical vein, clearly indicating that the hormones originate from the fetal pituitary. Oosterbaan and Swaab [3] also showed that while a rise in amniotic OT levels seems to reflect normal development of the human fetus, increased amniotic AVP levels may indicate fetal acidosis. Based on current knowledge, these processes are receptor mediated, with a central role being ascribed to the activation of the OT/AVP and their receptor systems, particularly with regard to uterine contractions as well as decidual activation [31]. It is perplexing that pregnancy continues until term despite increased fetal OT and OT receptors in human myometrium and deciduas [32]. Human pregnancy serum and placenta are known to degrade OT, which should be involved in regulating OT action. OT has a cystine ring structure at its $\mathrm{N}$-terminus that is essential for exerting its uterotonic activity. Until now three proteases have been identified concerning the degradation of OT/AVP. These include PLAP, postproline cleaving enzyme (EC3.4.21.16) and neutral endopeptidase (EC 3.4. 24.11) [33].

Although P-LAP degrades, the ring structure of OT at the peptide bond between $\mathrm{Cys}^{1}$ and $\mathrm{Tyr}^{2}$ and hydrolyzes the remaining bonds stepwise from the amino terminal. The other two proteases are not involved in opening the ring structure of OT $[6,34]$. Thus, only P-LAP should be regarded as oxytocinase. P-LAP is predominantly synthesized in placental syncytiotrophoblasts and increases in maternal blood with advancing pregnancy [35-39].

The change of balance between fetal OT/AVP and P-LAP due to fetal growth, and in response to various stimuli such as hypoxia in fetoplacental unit, likely triggers the onset of labor including preterm labor. Indeed, OT receptor antagonists are effective in inducing uterine quiescence in various animals including humans at term [40]. OT receptor antagonists have been reported to be more effective in the treatment of preterm labor than beta-agonists [41]. The degradation of these peptide hormones by P-LAP in the placenta is necessary in order to maintain homeostasis for both fetus and mother. While placental aminopeptidases regulate fetal bioactive peptides in the fetoplacental unit, they work also as a barrier of bioactive peptides between fetus and mother.

\section{Placental Aminopeptidase Changes}

Maternal serum APA and P-LAP activities in early mild preeclampsia patients are higher than those seen in normal pregnancy patients $[42,43]$. As the severity of preeclampsia 
progresses, both APA and P-LAP enzyme activity decrease, ultimately becoming lower than that measured during normal pregnancy $[42,44]$. It is likely that increased APA and P-LAP activity in maternal sera before, and immediately after, the appearance of preeclampsia is in response to the increased production of AngII/AVP from the fetus.

An understanding of the mechanisms underlying saltinduced hypertension in the Dahl salt-sensitive rat (DSS) is of considerable interest given the important role of sodium in hypertensive disorders [45]. Our laboratory has measured changes in renal APA activity and histological changes in the glomerulus of both DSS and Dahl salt-resistant (DSR) rats [46]. When low- $(0.3 \%)$ or high- $(8 \%-)$ salt diets were administered to DSR and DSS rats, only high-salt DSS rats revealed systolic blood pressure increases that reached approximately $150 \mathrm{mmHg}$ by week 10 , peaking at just under $250 \mathrm{mmHg}$ by week 18 . Several mechanisms have been suggested to underlie this response by DSS rats including sympathetic arousal, deficiency in nitric oxide, increased plasma endothelin-1, and an overactive RAS [46]. Although there is no evidence that the peripheral RAS is activated, the local renal RAS is stimulated in DSS rats suggesting a significant contribution by the RAS to the hypertension seen in this model [45]. Renal APA activity is elevated 3fold at week 10 in high-salt DSR rats, similar to that seen in high-salt DSS rats. Thereafter, it remained at this level. This increase in renal APA may serve to metabolize AngII, thus protecting the high-salt DSR rat from hypertension in response to high salt intake. Although APA activity in highsalt DSS rats increased 3-fold by week 10, it subsequently fell back and assumed the level of week 6 , by week 18 . This increase in renal APA at week 10 may serve to degrade AngII and temporarily protect this model. However, AngII levels in high-salt DSS rats at week 10 did not change despite increased APA activity. Since it is known that a highsalt diet increases intrarenal angiotensinogen levels in DSS rats, elevations in AngII levels would be anticipated [45]. Presumably these increases in AngII exceed the degradative capacity of APA and hypertension results. Changes seen in human maternal serum APA activity during preeclampsia are similar to changes measured in renal APA in the DSS rat model.

If the enzyme levels of maternal serum reflect the production rate in the placenta, then the decreased serum enzyme levels noted during severe preeclampsia may signify placental damage due to AngII/AVP-induced vasoconstriction. Thus, the trophoblastic degeneration seen during severe preeclampsia may be due to a failure to synthesize APA and P-LAP. We assayed P-LAP activity once at admission due to preterm labor (around week 31), at which time all patients were evidencing regular uterine contractions at $<15$ min intervals [47]. Although the specificity of P-LAP test is high (97\%), its sensitivity is low (29\%) for predicting the prognosis of preterm labor. High specificity of this test suggests a direct role of OT/P-LAP system in preterm labor. Serial assays of P-LAP could be useful as a rough guide for predicting the onset of labor, since the leveling off in P-LAP activity at 11 days prior to the onset of labor may be a useful marker for the final stage of gestation [48]. At term, increases in fetal OT overwhelm P-LAP, resulting in contractions of the uterus triggering the onset of labor. A similar process may also occur during preterm labor. During normal pregnancy, sufficient levels of P-LAP degrade OT and AVP, and APA deactivates AngII, thus protecting the mother. However, a drop in the activity of both enzymes permits elevated levels of vasoactive peptide hormones from the fetoplacental circulation to leak into the maternal circulation resulting in vasoconstriction (hypertension) and uterine contraction (onset of labor and preterm labor).

\section{APA-Deficient (KO) Mouse}

While pregnancy in humans and animals is normally characterized by a relative refractoriness to the hypertensive response associated with exogenously infused AngII, AngII sensitivity in the preeclampsia patient becomes higher reaching a level equivalent to, or greater than, that of nonpregnant women [49]. This phenomenon has been extensively studied as a most probable cause of preeclampsia; however, it remains controversial. The use of APA KO mice solved this question. APA KO mice are hypersensitive to exogenously administered AngII, strongly suggesting the involvement of APA in this AngII sensitivity [50].

Studies employing mice in which genes involved in angiotensin generation and encoding AngII receptors have been disrupted have provided information about the functions of these genes. Mice deficient in renin, angiotensinogen, $\mathrm{ACE}$, and the type 1 angiotensin receptor $\left(\mathrm{AT}_{1}\right)$ showed reduced BP, while APA KO mice evidenced a modest hypertension. The baseline systolic BP (SBP) is significantly elevated in $\mathrm{APA}^{-/-}$) mice compared with $\mathrm{APA}^{+/-}$and $\mathrm{APA}^{+/+}$ mice (3-month-old). The cDNA cloning of the B lymphocyte differentiation antigen, BP-1/6C3, identified $\mathrm{BP}-1 / 6 \mathrm{C} 3$ as APA and characterized the APA gene. After the production of BP-1/6C3/APA-deficient mice, little involvement of APA in immune system was shown [50]. Although the pathway of AngII metabolism in humans is still disputed, our investigations using APA knockout mice have shown that other enzymes possessing the ability to metabolize AngII in vitro, including neutral endopeptidase (EC3.4.24.11) [51], postproline cleaving enzyme (EC3.4.21.26) [52], and the recently described angiotensin-converting enzyme 2 (ACE2) [53], cannot compensate for the loss of APA [50]. Although the cleavage of C-terminal phenylalanine from AngII by ACE2 and postproline cleaving enzyme to generate a vasodilator Ang1-7 is able to influence BP and AngII concentrations, ACE2 does not counteract the hypertension due to APA deficiency. Therefore, APA is the essential enzyme with respect to RAS mediation hypertension.

When AngII was intraperitoneally infused over a period of four days $(750 \mu \mathrm{g} / \mathrm{kg} /$ day) in APA KO mice, SPB increased. It is evident that the magnitude of BP elevation is greater in $\mathrm{APA}^{-1-}$ mice than in wild-type mice (Figure 2). Following cessation of AngII infusion SBP dropped over the first day and then decreased to preinfusion levels. In contrast, SBP remained unchanged in control $\mathrm{APA}^{+/+}$and $\mathrm{APA}^{-/-}$ mice infused with saline. A deficiency in APA would be 


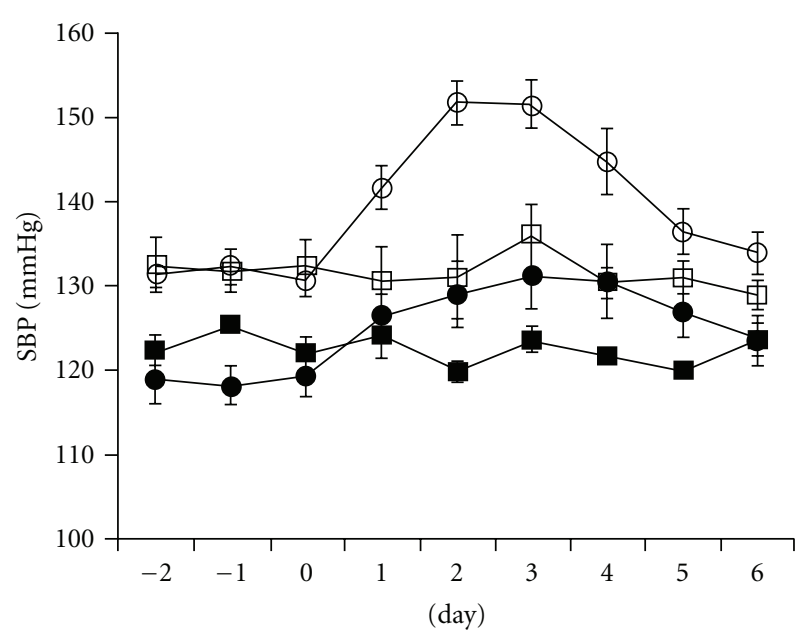

FIgUre 2: Effects of chronic AngII infusion on SBP. Daily changes of SBP in saline infusion $\left[\mathrm{APA}^{--}(\square)\right.$ and $\left.\mathrm{APA}^{+/+}(\boldsymbol{\square})\right]$ and AngII infusion $\left[\mathrm{APA}^{-/-}(\circ)\right.$ and $\left.\mathrm{APA}^{+/+}(\bullet)\right]$ mice. The implantation of osmotic minipupms was done on day 0 . Values are mean \pm SEM.

expected to increase the relative concentrations of AngII by protecting this peptide from degradation. Thus, the enhanced response to AngII infusion in APA-deficient mice is consistent with the biochemical property of APA in metabolizing AngII.

We measured SBP in the $\mathrm{APA}^{-/-}$and $\mathrm{APA}^{+/+}$mice ranging from 8 to $60 \mathrm{wk}$. SBP increased with advancing weeks (aging) in both the $\mathrm{APA}^{-/-}$and $\mathrm{APA}^{+/+}$mice. SBP in the $\mathrm{APA}^{-/-}$was higher than that in $\mathrm{APA}^{+/+}$mice, suggesting the possible involvement of APA in the hypertension associated with aging in humans. There is no developmental and histological difference in kidneys, heart, aorta, and brain between $\mathrm{APA}^{-/-}$and $\mathrm{APA}^{+/+}$mice at $12-$ 15 versus 49-60 weeks of age. APA KO mice did not show any developmental and histological abnormality in these organs. Although increased circulating levels of AngII in APA $\mathrm{KO}$ mice result in hypertension, it may not stimulate the synthesis of growth factor- $\beta$, which is capable of producing morphological changes such as arterial wall hypertrophy and cardiac abnormality. Since morphological changes in kidney were not seen in APA KO mice, we compared changes in urine volume and osmolality between $\mathrm{APA}^{-/-}$and $\mathrm{APA}^{+/+}$ mice. Although not statistically different, there were increases measured in APA KO mice, suggesting normal glomerular functioning.

\section{P-LAP-Deficient (KO) Mouse}

Oxytocin is the strongest uterotonic substance known and has been used widely to induce labor. However, success depends on treatment at the appropriate stage of pregnancy (just before the onset of labor). In any case, the uterus is more sensitive to OT as pregnancy progresses, to the point that labor readiness can be assessed by the amount of OT required to cause a contraction. The physiological importance of OT in modulating the initiation and progression of labor is still in dispute, since the regulating factor of OT sensitivity is unknown. Genetic analyses of putative mediators of labor in the mouse have provided insight into the molecular cascade that culminates in parturition. Although the initial characterization of the OT KO mice suggested that OT is not important in this species $[54,55]$, subsequent investigations have shown that OT is important for the precise timing of the onset of labor. Studies in $\mathrm{KO}$ mice also confirm important interrelationships between OT and prostaglandins (PGs) [54]. Previous studies using OT KO mice have shown that the prepartum interrelationship among OT, PG, and progesterone important for the precise timing of the onset of labor is around day 18.

Previously, we cloned the cDNA encoding human PLAP from the human placental cDNA library [56]. The major protein in insulin-responsive glucose transporter isotype GLUT4 vesicle in rat adipocytes was found to have aminopeptidase activity. The rat homologue of human PLAP is insulin-regulated aminopeptidase (IRAP) [57]. This protein was independently cloned at about the same time as P-LAP. Keller et al. reported that the P-LAP/IRAP KO mice do not have any difficulty in maintaining pregnancies and do not deliver their pups prematurely [58]. We have shown that P-LAP KO pregnant mice are hypersensitive to exogenously administered OT, and they deliver their pups prematurely, showing the possible involvement of P-LAP in this OT sensitivity during pregnancy. Since WT mice receiving OT (by implantation of osmotic minipumps) at rates of less than $1 \mathrm{U} /$ day showed the onset of labor at the expected time, we compared the effects of OT at infusion rates of 0 (vehicle only) and $1.0 \mathrm{U} /$ day, which were administered continuously from day 15.5 in WT and P-LAP KO mice, on the pregnant term. A significant shortening of term was observed in PLAP KO mice (onset of labor, $3.3 \pm 0.5$ days after pump placement) in comparison with WT mice (onset of labor, $4.3 \pm 0.3$ days after pump placement) without administration of OT (vehicle only, $P<.05$, Figure 2 ), indicating that $\mathrm{P}$ LAP KO pregnant mice deliver their pups prematurely. When mice received $1.0 \mathrm{U} /$ day OT, the difference of onset of labor between WT and P-LAP KO mice was more evident. PLAP KO mice resulted in premature delivery (onset of labor $2.3 \pm 0.9$ days after pump placement with $1.0 \mathrm{U} /$ day OT) in comparison with WT mice (onset of labor $4.5 \pm 0.4$ days after pump placement with $1.0 \mathrm{U} /$ day OT, $P<.05$ ) (Figure $3(\mathrm{a})$ ). There were significant differences concerning duration of pregnancy comparing with and without administration of OT in P-LAP KO mice $(P<.05)$.

We have shown that AVP is hydrolyzed by P-LAP at least 3 times more quickly than OT when monitored via the release of the Tyr residue [7]. Recently, Wallis et al. [59] have shown that AVP is a physiological substrate for PLAP using P-LAP KO mice in vitro. With the administration of 1.0 U AVP intramuscularly in P-LAP KO and WT mice, there was a statistically significant decrease in both urine volume and water intake/day in both groups. We observed a statistically significant difference in urine volume between P-LAP KO and WT mice. KO mice on both P-LAP and APA showed that OT and AngII sensitivity is regulated by both aminopeptidases. 


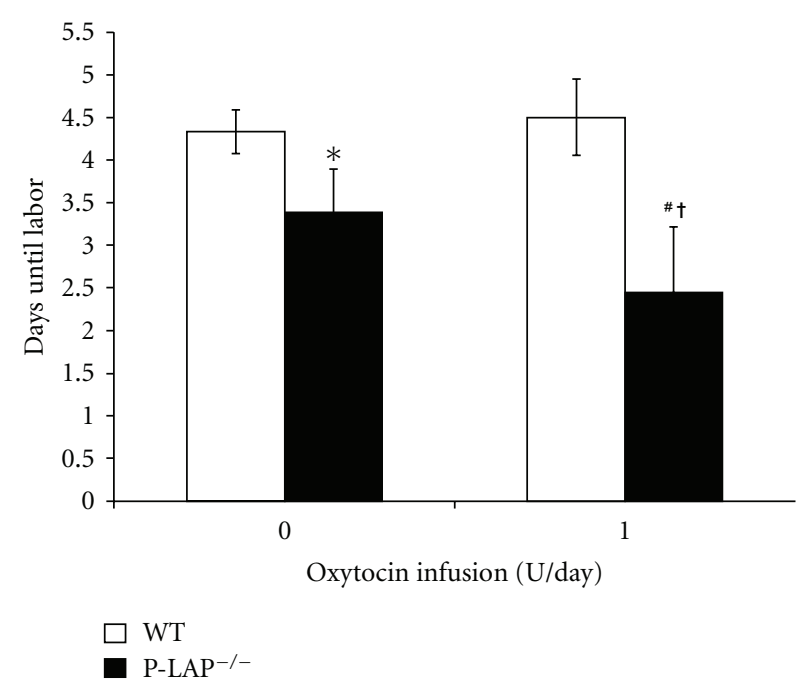

(a)

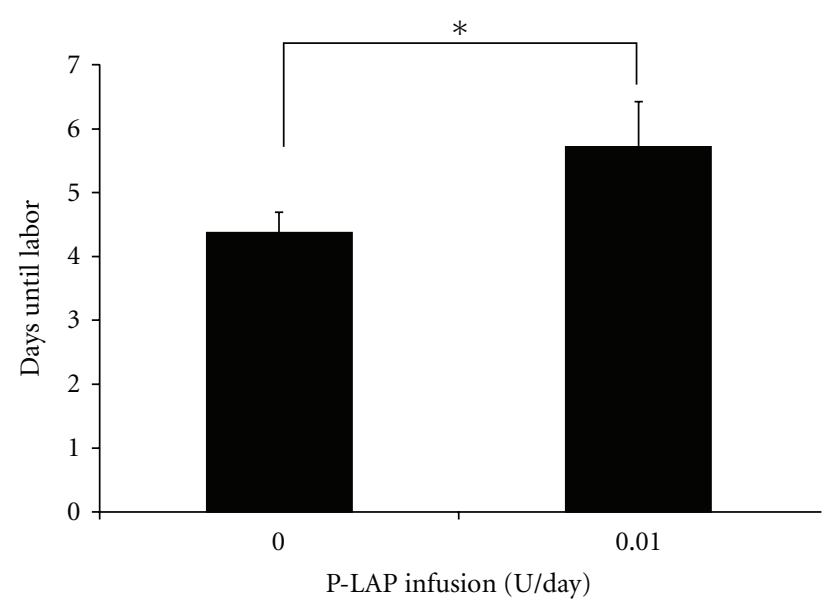

(b)

Figure 3: (a) Effect of OT infusion on the pregnant time in both WT and P-LAP KO mice. Values are expressed as means \pm SD. ${ }^{*} P<.05$; WT mice versus P-LAP KO mice in vehicle only, ${ }^{\#} P<.05$; WT mice versus P-LAP KO mice in 1 U/day OT, ${ }^{\dagger} P<.05$; P-LAP KO mice in vehicle versus P-LAP KO mice in $1 \mathrm{U} /$ day OT. (b) Effect of recombinant P-LAP on the pregnant time in WT mice. Values are expressed as means $\pm \mathrm{SD} .{ }^{*} P<.05$; vehicle only versus $0.01 \mathrm{U} /$ day P-LAP.

\section{APA Acts as an Antihypertensive Agent}

The SHR is widely used in cardiovascular research as a model of human hypertension, and it offers the opportunity to understand the mechanisms underlying this disease state. BP can be normalized in SHRs with angiotensin receptor blockers (ARBs) and ACE inhibitors, suggesting the involvement of the RAS. Although SHRs do not evidence elevated renin activity or increased plasma AngII concentrations relative to their normotensive counterpart Wistar-Kyoto (WKY) rats, they do possess a supersensitivity to AngII [60]. These results suggest that the SHR is more responsive to the vasoconstrictive effects of AngII than WKY rats. Since we have shown that the administration of a mixture of APA and aminopeptidase N (APN) (EC 3.4.11.2) purified from human placenta reduces BP in SHRs, we have tested the effect of recombinant APA on BP in SHRs [61]. We found that bolus intravenous injections of recombinant APA at various doses significantly decreased systolic BP in SHRs at the 3-hour time point. Among them, the $0.016 \mathrm{mg} / \mathrm{kg}$ dose of APA caused a gradual decrease in systolic BP, reaching approximately $-40 \mathrm{mmHg}$ by $24 \mathrm{~h}$. Much higher doses of APA revealed a sharp decline of BP (approximately $50 \mathrm{mmHg}$ at $3 \mathrm{~h}$ ); however, they showed the reversal of its antihypertensive effect after $3 \mathrm{~h}$ [60].

Song and Healy [62] have reported that APA levels in glomeruli increased with the infusion of a subpressor dose of AngII in normotensive rats. They also showed that treatment with an ACE inhibitor reduced kidney APA activity in SHRs, suggesting that APA expression may be positively coupled with AngII levels.

Our laboratory has also shown that APA activity increased with the addition of AngII to a primary culture of normal placental trophoblasts [63]. We determined that
AngII stimulated the proliferation of trophoblastic cells via the $\mathrm{AT}_{1}$ receptor subtype linked to protein kinase C/MAPK-dependent signaling pathways [64]. APA activity was upregulated during AngII-induced cell proliferation; thus, it appears that increased levels of either AngII or APA result in a compensatory response, presumably representing an attempt to maintain homeostasis. This may explain why the highest dose of APA resulted in the greatest reversal of the antihypertensive effect. The lower doses of APA may be below the threshold to induce compensatory increases in circulating AngII.

Because the glutamic acid residue in the GAMEN motif is important for the enzymatic action of the M1aminopeptidase family [65], we replaced Glu360 with a glutamine residue (APA E360Q). As expected, APA E360Q did not show any hydrolytic activity against the fluorogenic synthetic substrate Glu-MCA or AngII (data not shown). APA E360Q (no APA enzymatic activity) did not show any effect on SBP of SHRs. The $0.016 \mathrm{mg} / \mathrm{kg}$ dose of APA failed to influence SBP except for a slight, but nonsignificant, decline at 48 hours in Wistar-Kyoto (WKY) rats. Although a number of pathogenic factors have been proposed to underlie the hypertension of SHRs [66], the present results suggest an important role for APA-mediated degradation of AngII. We have shown that renal APA is involved in the development of hypertension and the regulation of BP in SHRs [67].

We compared the antihypertensive effects of daily bolus injections of APA $(0.016 \mathrm{mg} / \mathrm{kg})$ against continuous infusion of the ARB candesartan $(0.1 \mathrm{mg} / \mathrm{kg} /$ day $)$ over 5 days in SHRs. The magnitude of the antihypertensive effect by APA and candesartan was similar: APA, $175.8 \pm 13.5 \mathrm{mmHg}$ to $147.6 \pm 16.3 \mathrm{mmHg}$ at $24 \mathrm{~h} ; \mathrm{ARB}, 169.5 \pm 10.3 \mathrm{mmHg}$ to $137.4 \pm 11.0 \mathrm{mmHg}$ at $24 \mathrm{~h}$ (Figure 4 ). The antihypertensive 


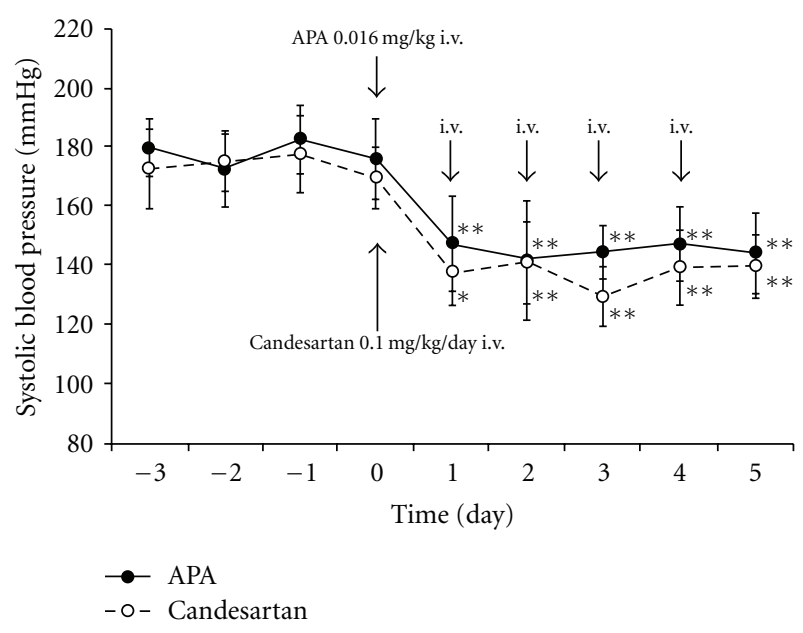

Figure 4: Comparison of APA $(0.016 \mathrm{mg} / \mathrm{kg})$ and candesartan on $\mathrm{BP}$ in SHRs. Intravenous injection of recombinant APA $(n=5)$ and candesartan $(n=5)$ significantly decreased SBP for $5 \mathrm{~d}$ in SHRs. The magnitude of the antihypertensive effects of APA $(0.016 \mathrm{mg} / \mathrm{kg})$ and ARB $(0.1 \mathrm{mg} / \mathrm{kg})$ was similar. APA $(0.016 \mathrm{mg} / \mathrm{kg})$ : bolus injection every day for $5 \mathrm{~d}$; candesartan $(0.1 \mathrm{mg} / \mathrm{kg})$ : continuous infusion by osmotic minipumps for $5 \mathrm{~d}$. ${ }^{*} P<.05$, ${ }^{* *} P<.01$ compared with pretreatment period.

effects induced by a bolus injection of APA $(0.016 \mathrm{mg} / \mathrm{kg})$ are similar to those obtained with continuous drop infusion of nitroprusside $(0.5-5 \mathrm{mg} / \mathrm{kg} / \mathrm{min})$ in humans [68]. Other laboratories have reported that intravenous administration of the ARB Dup753 $(10 \mathrm{mg} / \mathrm{kg})$ decreased blood pressure in SHRs for at least 24 hours, and intravenous injection of the ACE inhibitor captopril $(2 \mathrm{mg} / \mathrm{kg})$ reduced blood pressure in SHRs for 3 hours [60]. Although the differing delivery methods make comparison of the present results somewhat difficult, it does appear that the application of a low dose of APA was equivalent to an ARB and ACE inhibitor with respect to antihypertensive efficacy. The effective dose of APA in the present study was about one-tenth that of candesartan. Thus, in a comparison of a bolus injection of APA (MW $109 \mathrm{kDa}$ ) and a continuous infusion of candesartan (MW $440 \mathrm{kDa}$ ) for 36 hours, APA possesses a 2300 -fold advantage in efficacy over candesartan. Our data suggest that AngII degradation in blood is a much more effective approach than blocking AngII receptor binding in treating imminent hypertension as resulting from hypertensive encephalopathy, apoplexy, and acute heart failure, and acute dissection of aorta.

\section{APA is an Antihypertensive Drug Candidate in Pregnancy}

It is known that the administration of ACE inhibitors causes hypotension which can be lethal to the human fetus. This suggests an important role for AngII in the fetoplacental circulation [69]. Taken together, these findings present a treatment dilemma since the increased synthesis of AngII by the fetus significantly contributes to preeclampsia; while vasoconstriction of the fetoplacental circulation may be of primary importance in preeclampsia [70]. However, the administration of conventional antihypertensive agents to the mother is detrimental to the fetus.

Two animal models of preeclampsia have been reported. Davisson and colleagues [71] noted a spontaneous mouse syndrome that approximates preeclampsia. These investigators placed thoracic aortic telemeters in nonpregnant female $\mathrm{BPH} / 5$ and C57BL/6 mice. Following recovery from surgery, five days of baseline mean arterial pressure (MAP) recordings were taken. Next, strain-matched timed pregnancies were initiated. Prior to pregnancy, members of each strain indicated comparable total urinary protein levels; however, the $\mathrm{BPH} / 5$ mice evidenced an elevated MAP compared with the C57BL/6 mice. Although blood pressures were stable during the initial two weeks of pregnancy in members of both strains, at the beginning of the last trimester MAP became elevated in the $\mathrm{BPH} / 5$ mice peaking just prior to delivery and then returned to baseline following delivery. There was also evidence of late gestational proteinuria and progressive glomerulosclerosis. No such changes were measured in members of the C57BL/6 strain. Further, the $\mathrm{BPH} / 5$ mice produced smaller litter sizes even though the number of fetuses was comparable to C57BL/6 mice earlier in gestation. A second preeclampsia animal model was developed by Maynard et al. [72]. These investigators observed increases in placental soluble fms-like tyrosine kinase 1 (sFlt1) in preeclampsia patients accompanied by decreases in circulating VEGF, and placental growth factor (PlGF). The administration of VEGF and PIGF corrected the resulting endothelial dysfunction and suggested the following experiment. Pregnant rats were administered sFlt1, a VEGF, and PIGF antagonist, which prompted the development of proteinuria and glomerular endotheliosis, both characteristic of preeclampsia. The authors concluded that elevated and excessive levels of circulating sFlt1 are a major contributor to the pathogenesis of preeclampsia.

Since the diagnosis of preeclampsia is determined essentially by increased BP, we used pregnant SHRs as a model of preeclampsia. Bestatin is a low-molecular-weight peptide that inhibits APA and APN. Previously, we showed that the administration of bestatin to pregnant rats results in fetoplacental growth restriction [73]. We have also found that bestatin administration in pregnant rats results in the disappearance of BP decline during late gestation, which is commonly observed in both SHR and WKY pregnant rats. In addition, bestatin administration to pregnant rats resulted in increased proteinuria [70].

We have tested the effects of APA and ARB on hypertension in pregnant SHRs. Bolus injections of APA and ARB were administered via osmotic minipumps. The doses were as follows: recombinant APA $(0.016-0.16 \mathrm{mg} / \mathrm{kg} /$ day $)(n=$ 5) and ARB (candesartan: CV-11974, Takeda Pharmaceutical Co. Ltd, Osaka, Japan; $0.1-1 \mathrm{mg} / \mathrm{kg} /$ day $)(n=5)$. Initial doses of ARB were titrated to match those used for human hypertension. Bolus doses of each drug injected were doubled daily up to 10 -fold until the end of drug treatment from day 10 to day 20. Since mean BP differed across groups, 


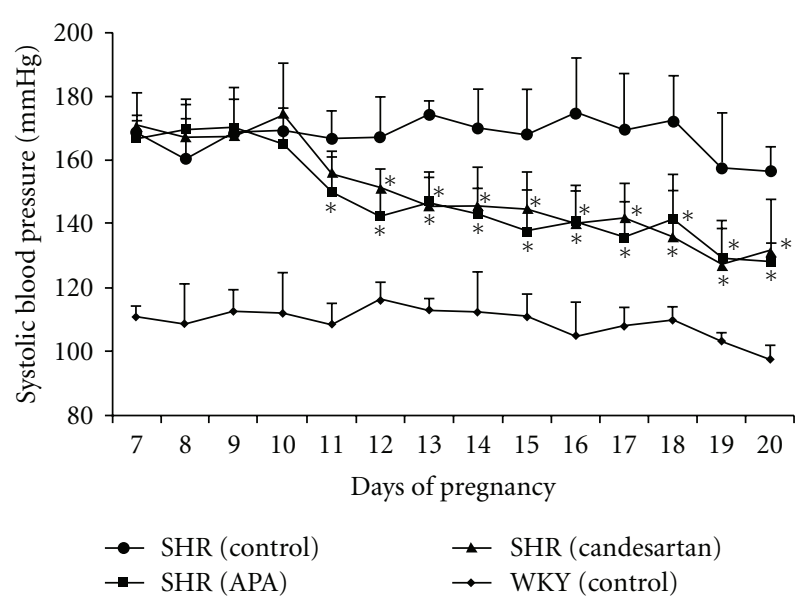

FIGURE 5: Changes of SBP during mid- and late-term pregnancy in SHRs with and without administration of APA and candesartan and WKYs without administration of any drugs. SHR (control, $n=5$ ), SHR (APA: $0.016-0.16 \mathrm{mg} / \mathrm{kg} / \mathrm{day}, n=5$ ), SHR (candesartan: 0.1$1 \mathrm{mg} / \mathrm{kg} /$ day, $n=5$ ), and WKYs (control, $n=5$ ).

the changes in BP following administration of drugs were compared with baseline BP measured prior to the initiation of the experiment. Figure 5 shows the changes in systolic BP during mid and late pregnancy (from day 10 to day 20) in SHRs with administration of candesartan and APA. Changes in systolic BP during mid and late pregnancy in pregnant WKYs without administration of any drugs (control) are also shown. The magnitude of antihypertensive effects of APA and candesartan was very similar $(-30 \mathrm{mmHg})$ at day 20. There were no differences in fetal and placental weights comparing control SHRs and drug-administered groups. Fetal and placental weights in SHRs were significantly lower than those of WKY rats. These results are consistent with our previous data and the data of others. There were no differences in fetal kidney and heart weights between drugadministrated groups and the control. Although there were many mature renal glomeruli, which contain red blood corpuscles, in members of the APA and control groups, few were found in members of the ARB group.

It is known that both ACE inhibitor and ARB therapy in the second and third trimesters of pregnancy have been associated in humans with fetal renal damage, oligohydroamnios, anhydroamnios, and even fetal death [74]. Recently, Bowen and colleagues [75] have reported the increased frequency of pregnant women with ACE inhibitor exposure. Since both block AngII action via degradation and binding of AngII, respectively, the antihypertensive effect results from a loss of AngII stimulation in pregnant SHRs. The antihypertensive effects of APA and candesartan were maintained by increasing the dose with advancing gestation, suggesting that AngII synthesis increases over time in pregnant SHRs. This likely represents increased leakage of AngII from the fetoplacental unit into maternal circulation with advancing gestation. Our study suggests an important role for APAmediated degradation of AngII in hypertension in pregnant SHRs. Since APA is a large molecule that does not cross the placenta, APA may be a useful drug for the treatment of preeclampsia.

\section{P-LAP as a Possible Agent for Treatment of Preterm Delivery}

We administered recombinant P-LAP continuously from day 15.5 in WT mice (Figure 3(b)). Significant elongation in the onset of labor was observed in WT mice in response to P-LAP infused at $0.01 \mathrm{U} /$ day (onset of labor $5.7 \pm 0.7$ days after pump placement with $0.01 \mathrm{U} /$ day P-LAP versus $4.4 \pm 0.3$ days for vehicle infused, $P<.05$ ). Results from this preliminary investigation concerning the administration of recombinant P-LAP at $0.1 \mathrm{U} /$ day continuously from day 15.5 in WT mice indicated elongation of the onset of labor without any negative effects on mother and pups (data not shown). We used this same daily dose of recombinant P-LAP (0.01 U/day) in a subsequent experiment. Both parturition time and number of viable pups in the P-LAP-treated group were not significantly different from those in vehicle group. Specifically, the number of pups in the vehicle group was $5.8 \pm 1.3$ pups/litter, and in the P-LAP group $6.0 \pm$ 1.8 pups/litter [76].

As mentioned previously, the prepartum interrelationship among OT, PG, and progesterone important for the precise timing of the onset of labor is around day 18 in mouse. The administration of recombinant P-LAP surpassed these phenomena and thus delayed the onset of labor in mouse. On the other hand, we [76] and Imamura et al. [77] have shown that OT at higher doses was able to precipitate labor, indicating that augmentation of uterine contraction before normal labor is achievable despite low uterine OTR levels and elevated plasma progesterone concentrations if the level of OT is sufficiently high. Therefore, it is suggested that the regulation of the onset of labor mainly depends on OT, and its degradation by P-LAP and is therefore, independent of both PG and progesterone. Indeed, OT exaggerates the inherent pattern of uterine motility, which often becomes clinically evident during the last trimester and increases as term is approached. Therefore, OT is the most common method of induction of human labor. OTR antagonists are effective in inducing uterine quiescence in various animal species including humans at term. OTR antagonists have been reported to be effective in the treatment of preterm labor compared with beta agonists [78]. However, these agents are small molecules and therefore cross the placenta and have various pharmacological effects on the fetus [14, $15,79]$. Since P-LAP has a molecular weight of 160 $165 \mathrm{kDa}$, it does not cross the placenta. Thus, P-LAP might be a useful agent for the treatment of preterm labor in pregnancy. In addition, P-LAP may be useful in avoiding the onset of midnight labor, which is troublesome for all obstetricians. Since P-LAP and APA are large molecules that do not cross the placental barrier, they represent promising agents to treat preeclampsia and preterm labor by degrading bioactive hormones derived from fetoplacental circulation. 


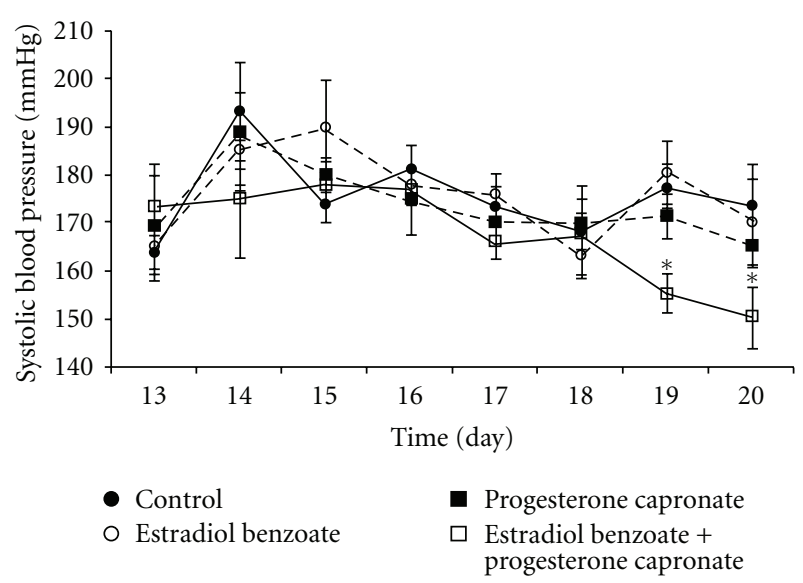

FIGURE 6: Changes of daily SBP in SHRs during middle and late pregnancy under administration of sex steroids and olive oil (control). Only E with P administration reduced significantly SBP at late pregnancy compared with those in others (at days 19, 20). $* P<.001$.

\section{Final Comments}

The ultimate goal regarding treatment for both preeclampsia and preterm labor must be maternally directed without influencing the fetoplacental unit. We have previously reported positive effects with estradiol and progesterone treatment for severe preeclampsia [80]. In 1941, G. V. Smith and O. W. Smith [81] reported the successful treatment of severe preeclampsia with estradiol and progesterone. However, very little attention was paid to this treatment approach due to the potential teratogenicity of these compounds. Even so at present, it is common to use estradiol and progesterone in human-assisted reproduction during the early days of pregnancy. These positive outcomes in preeclampsia and/or preterm labor are likely via activation of placental aminopeptidases that degrade vasoactive hormones thus reducing maternal BP [80]. We have shown that progesterone, and probably estrogen, increases APA levels in human trophoblastic cells. We employed the RNase protection assay method to increase accuracy and sensitivity in determining APA mRNA levels [82]. Progesterone has recently been reevaluated as a tocolytic agent. However, estrogen is not commonly used during pregnancy except to assist reproduction. We have shown that exogenously administered estradiol benzoate at $1 \mu \mathrm{g} /$ day or less in pregnant rats (days12-19) had no effect on pup survival and fetoplacental growth. However, at a dose of $10 \mu \mathrm{g} / \mathrm{day}$ or more, there was a tendency toward reduced fetoplacental growth. Thus, it is important to closely monitor the dosage of estrogen administered during pregnancy [83].

We have shown the effects of $17 \beta$-estradiol benzoate (E) and 17- $\alpha$ hydroxyprogesterone capronate (P) on BP and fetoplacental growth in SHRs. E $(10 \mu \mathrm{g} /$ day $)$ and $\mathrm{P}$ $(2 \mathrm{mg} /$ day) were administered intraperitoneally to pregnant SHRs from day 16 to 19 . These steroids had no effect on the number of pups delivered; however, there were decreases in birth weights and placenta weights except in the case of placentae by E accompanied with P. Mean SBP decreased from days14-16 to days 18-20 of pregnancy in SHRs. Although E and P had no effect on BP, E accompanied with P significantly decreased BP as compared with control SHRs at days 19 and 20 of pregnancy (unpublished data). We also measured APA activity in the maternal renal cortex in this experiment. Treatment with both $\mathrm{E}$ and $\mathrm{P}$ showed a tendency to increase APA activity, but this effect was not statistically significant compared with control (olive oil). However, APA activity in the kidney was significantly increased by E accompanied with P (Figure 6, unpublished data).

We continued such treatment in appropriate cases and found that both mother and newborn remained in good health. We have followed several severe preeclampsia cases. One female baby treated with only estradiol and progesterone is now 36 years old and has two healthy children, suggesting no negative effects. This treatment approach could be used for preeclampsia on an interim basis until, hopefully, aminopeptidases are approved as drugs for this purpose.

Barker's hypothesis [84] suggests that reduced fetal growth is correlated with the occurrence of a number of chronic conditions later in life including coronary heart disease, stroke, diabetes, hypertension, and depression. Given the ever increasing world-wide incidences of preeclampsia and preterm labor, it is imperative that new agents be developed to safely prolong gestation. We believe the use of aminopeptidases hold promise in this regard.

\section{References}

[1] F. Broughton-Pipkin and E. M. Symonds, "Factors affecting angiotensin II concentrations in the human infant at birth," Clinical Science and Molecular Medicine, vol. 52, no. 5, pp. 449456, 1977.

[2] J. C. P. Kingdom, J. McQueen, J. M. C. Connell, and M. J. Whittle, "Fetal angiotensin II levels and vascular (type I) angiotensin receptors in pregnancies complicated by intrauterine growth retardation," British Journal of Obstetrics and Gynaecology, vol. 100, no. 5, pp. 476-482, 1993.

[3] H. P. Oosterbaan and D. F. Swaab, "Amniotic oxytocin and vasopressin in relation to human fetal development and labour," Early Human Development, vol. 19, no. 4, pp. 253$262,1989$.

[4] T. Chard, C. N. Hudson, C. R. W. Edwards, and N. R. H. Boyd, "Release of oxytocin and vasopressin by the human foetus during labour," Nature, vol. 234, no. 5328, pp. 352-354, 1971.

[5] H. Sakura, T. Y. Lin, M. Doi, S. Mizutani, and Y. Kawashima, "Purification and properties of oxytocinase, a metalloenzyme," Biochemical International, vol. 2, pp. 173-179, 1981.

[6] S. Mizutani, S. Sumi, K. Oka, R. Yamada et al., "In vitro degradation of oxytocin by pregnancy serum, placental subcellular fractions and purified placental aminopeptidases," Experimental and Clinical Endocrinology, vol. 86, no. 3, pp. 310-316, 1985.

[7] M. Tsujimoto, S. Mizutani, H. Adachi, M. Kimura, H. Nakazato, and Y. Tomoda, "Identification of human placental leucine aminopeptidase as oxytocinase," Archives of Biochemistry and Biophysics, vol. 292, no. 2, pp. 388-392, 1992. 
[8] S. Mizutani, K. Okano, E. Hasegawa et al., "Aminopeptidase A in human placenta," Biochimical Biophsics Acta, vol. 678, pp. 168-170, 1981.

[9] S. Mizutani, H. Akiyama, and O. Kurauchi, "In vitro degradation of angiotensin II (A-II) by human placental subcellular fractions, pregnancy sera and purified placental aminopeptidases," Acta Endocrinologica, vol. 110, no. 1, pp. 135-139, 1985.

[10] S. Mizutani, K. Naruse, A. Hattori, M. Tsujimoto, and H. Kobayashi, "Physiological and pathophysiological roles of placental aminopeptidase in maternal sera: possible relation to preeclampsia and preterm delivery," Expert Opinion on Medical Diagnostics, vol. 3, no. 5, pp. 479-491, 2009.

[11] C. W. Redman and I. L. Sargent, "Latest advances in understanding preeclampsia," Science, vol. 308, no. 5728, pp. 1592 1594, 2005.

[12] J. M. Roberts, "Pregnancy-related hypertension," in MaternalFetal Medicine, R. K. Creasy and R. Resnik, Eds., pp. 859-899, Saunders, Philadelphia, Pa, USA, 5th edition, 2004.

[13] T. P. Dezen and E. Lynch, "Title of subordinate document," in For Preterm Birth Rate, March of Dimes Foundation, November 2009, http//www.marchofdimes.com/ title of subordinate document.

[14] S. E. Fletcher, D. A. Fyfe, C. L. Case, H. B. Wiles, J. K. Upshur, and R. B. Newman, "Myocardial necrosis in a newborn after long-term maternal subcutaneous terbutaline infusion for suppression of preterm labor," American Journal of Obstetrics and Gynecology, vol. 165, no. 5 I, pp. 1401-1404, 1991.

[15] T. Thorkelsson and J. L. Loughead, "Long-term subcutaneous terbutaline tocolysis: report of possible neonatal toxicity," Journal of Perinatology, vol. 11, no. 3, pp. 235-238, 1991.

[16] P. G. Pryde and R. Mittendorf, "Contemporary usage of obstetric magnesium sulfate: indication, contraindication, and relevance of dose," Obstetrics and Gynecology, vol. 114, no. 3, pp. 669-673, 2009.

[17] M. Ishii, A. Hattori, Y. Numaguchi et al., "The effect of recombinant aminopeptidase A (APA) on hypertension in pregnant spontaneously hypertensive rats (SHRs)," Early Human Development, vol. 85, no. 9, pp. 589-594, 2009.

[18] C. P. Taliercio, J. B. Seward, and D. J. Driscoll, "Idiopathic dilated cardiomyopathy in the young: clinical profile and natural history," Journal of the American College of Cardiology, vol. 6, no. 5, pp. 1126-1131, 1985.

[19] S. Mizutani and Y. Tomoda, "Effects of placental proteases on maternal and fetal blood pressure in normal pregnancy and preeclampsia," American Journal of Hypertension, vol. 9, no. 6, pp. 591-597, 1996.

[20] H. Taira, S. Mizutani, O. Narita, and Y. Tomoda, "Angiotensin I-converting enzyme in human placenta," Placenta, vol. 6, no. 6, pp. 543-549, 1985.

[21] H. Yagami, O. Kurauchi, Y. Murata, T. Okamoto, S. Mizutani, and Y. Tomoda, "Expression of angiotensin-converting enzyme in human placenta and its physiologic role in the fetal circulation," Obstetrics and Gynecology, vol. 84, no. 3, pp. 453457, 1994.

[22] W. Raasch, O. Jöhren, S. Schwartz, A. Gieselberg, and P. Dominiak, "Combined blockade of AT1-receptors and ACE synergistically potentiates antihypertensive effects in SHR," Journal of Hypertension, vol. 22, no. 3, pp. 611-618, 2004.

[23] M. Boschmann, U. Kreuzberg, S. Engeli et al., "The effect of oral glucose loads on tissue metabolism during angiotensin II receptor and beta-receptor blockade in obese hypertensive subjects," Hormone and Metabolic Research, vol. 38, no. 5, pp. 323-329, 2006.
[24] S. Mizutani, M. Ishii, A. Hattori et al., "New insights into the importance of aminopeptidase A in hypertension," Heart Failure Reviews, vol. 13, no. 3, pp. 273-284, 2008.

[25] G. Wolf, S. Mentzel, and K. J. M. Assmann, "Aminopeptidase A: a key enzyme in the intrarenal degradation of angiotensin ii," Experimental Nephrology, vol. 5, no. 5, pp. 364-369, 1997.

[26] J. W. Wright, B. J. Yamamoto, and J. W. Harding, "Angiotensin receptor subtype mediated physiologies and behaviors: new discoveries and clinical targets," Progress in Neurobiology, vol. 84, no. 2, pp. 157-181, 2008.

[27] R. K. Creasy, R. Resnik, and J. D. Iams, Eds., Maternal-Fetal Medicine: Principles and Practice, Elsevier, New York, NY, USA, 5 th edition, 2004.

[28] F. Arias and P. Tomich, "Etiology and outcome of low birth weight and preterm infants," Obstetrics and Gynecology, vol. 60, no. 3, pp. 277-281, 1982.

[29] G. C. Liggins, P. C. Kennedy, and L. W. Holm, "Failure of initiation of parturition after electrocoagulation of the pituitary of the fetal lamb," American Journal of Obstetrics and Gynecology, vol. 98, no. 8, pp. 1080-1086, 1967.

[30] G. C. Liggins, S. A. Grieves, J. Z. Kendall, and B. S. Knox, "The physiological roles of progesterone, oestradiol-17 $\beta$ and prostaglandin F $2 \alpha$ in the control of ovine parturition," Journal of Reproduction and Fertility, vol. 16, supplement, pp. 16-10, 1972.

[31] A. M. Blanks and S. Thornton, "The role of oxytocin in parturition," British Journal of Obstetrics and Gynaecology, vol. 110, supplement 20, pp. 46-51, 2003.

[32] A.-R. F. Fuchs Fuchs, P. Husslein, and M. S. Soloff, "Oxytocin receptors in the human uterus during pregnancy and parturition," American Journal of Obstetrics and Gynecology, vol. 150, no. 6, pp. 734-741, 1984.

[33] S. Mizutani and Y. Tomoda, "Oxytocinase: placental cystine aminopeptidase or placental leucine aminopeptidase (PLAP)," Seminars in Reproductive Endocrinology, vol. 10, no. 2, pp. 146-153, 1992.

[34] M. Naruki, S. Mizutani, K. Goto et al., "Oxytocin is hydrolyzed by an enzyme in human placenta that is identical to the oxytocinase of pregnancy serum," Peptides, vol. 17, no. 2, pp. 257-261, 1996.

[35] S. Mizutani, M. Yoshino, and M. Oya, "Placental and non placental leucine aminopeptidases during normal pregnancy," Clinical Biochemistry, vol. 9, no. 1, pp. 16-18, 1976.

[36] N. Yamahara, S. Nomura, T. Suzuki et al., "Placental leucine aminopeptidase/oxytocinase in maternal serum and placenta during normal pregnancy," Life Sciences, vol. 66, no. 15, pp. 1401-1410, 2000.

[37] M. Klimek, L. Wicherek, T. J. Popiela, K. Skotniczny, and B. Tomaszewska, "Changes of maternal ACTH and oxytocinase plasma concentrations during the first trimester of spontaneous abortion," Neuroendocrinology Letters, vol. 26, no. 4, pp. 342-346, 2005.

[38] L. Wicherek, M. Dutsch-Wicherek, P. Mak, and M. Klimek, "The role of RCAS1 and oxytocinase in immune tolerance during pregnancy," Fetal Diagnosis and Therapy, vol. 20, no. 5, pp. 420-425, 2005.

[39] T. Nagasaka, S. Nomura, M. Okamura et al., "Immunohistochemical localization of placental leucine aminopeptidase/oxytocinase in normal human placental, fetal and adult tissues," Reproduction, Fertility and Development, vol. 9, no. 8, pp. 747-753, 1997.

[40] O. N. Richter, C. Dorn, P. Van De Vondel, U. Ulrich, and J. Schmolling, "Tocolysis with atosiban: experience in the management of premature labor before 24 weeks of 
pregnancy," Archives of Gynecology and Obstetrics, vol. 272, no. 1, pp. 26-30, 2005.

[41] T. Engstrøm, P. Bratholm, H. Vilhardt, and N. J. Christensen, "Effect of oxytocin receptor and $\beta 2$-adrenoceptor blockade on myometrial oxytocin receptors in parturient rats," Biology of Reproduction, vol. 60, no. 2, pp. 322-329, 1999.

[42] S. Mizutani, H. Akiyama, O. Kurauchi, H. Taira, O. Narita, and Y. Tomoda, "Plasma angiotensin II and serum placental leucine aminopeptidase (P-LAP) in pre-eclampsia," Archives of Gynecology, vol. 236, no. 3, pp. 165-172, 1985.

[43] S. A. Mohamed, S. Mizutani, H. T. Salem et al., "Changes of placental proteases, which degrade vasoactive peptides, in maternal sera at the onset of preeclampsia," Medical Science Research, vol. 23, no. 2, pp. 123-126, 1995.

[44] S. Mizutani, R. Yamada, O. Kurauchi, Y. Ito, O. Narita, and Y. Tomoda, "Serum aminopeptidase A (AAP) in normal pregnancy and pregnancy complicated by pre-eclampsia," Archives of Gynecology, vol. 240, no. 1, pp. 27-31, 1987.

[45] H. Kobori, A. Nishiyama, Y. Abe, and L. G. Navar, "Enhancement of intrarenal angiotensinogen in Dahl salt-sensitive rats on high salt diet," Hypertension, vol. 41, no. 3 I, pp. 592-597, 2003.

[46] M. Nomura, S. Nomura, T. Mitsui et al., "Possible involvement of aminopeptidase a in hypertension and renal damage in Dahl salt-sensitive rats," American Journal of Hypertension, vol. 18, no. 4, pp. 538-543, 2005.

[47] H. Kozaki, A. Itakura, M. Okamura, Y. Ohno, K. Wakai, and S. Mizutani, "Maternal serum placental leucine aminopeptidase (P-LAP)/oxytocinase and preterm delivery," International Journal of Gynecology and Obstetrics, vol. 73, no. 3, pp. 207213,2001

[48] S. Mizutani, H. Hayakawa, and H. Akiyama, "Simultaneous determinations of plasma oxytocin and serum placental leucine aminopeptidase (P-LAP) during late pregnancy," Clinical Biochemistry, vol. 15, no. 3, pp. 141-145, 1982.

[49] N. F. Gant, G. L. Daley, S. Chand, P. J. Whalley, and P. C. MacDonald, "A study of angiotensin II pressor response throughout primigravid pregnancy," Journal of Clinical Investigation, vol. 52, no. 11, pp. 2682-2689, 1973.

[50] T. Mitsui, S. Nomura, M. Okada et al., "Hypertension and angiotensin II hypersensitivity in aminopeptidase A-deficient mice," Molecular Medicine, vol. 9, no. 1-2, pp. 57-62, 2003.

[51] J. T. Gafford, R. A. Skidgel, E. G. Erdös, and L. B. Hersh, "Human kidney "enkephalinase", a neutral metalloendopeptidase that cleaves active peptides," Biochemistry, vol. 22, no. 13, pp. 3265-3271, 1983.

[52] S. Mizutani, S. Sumi, O. Suzuki, O. Narita, and Y. Tomoda, "Postproline endopeptidase in human placenta," Biochimica et Biophysica Acta, vol. 786, pp. 113-117, 1984.

[53] S. R. Tipnis, N. M. Hooper, R. Hyde, E. Karran, G. Christie, and A. J. Turner, "A human homolog of angiotensinconverting enzyme: cloning and functional expression as a captopril-insensitive carboxypeptidase," Journal of Biological Chemistry, vol. 275, no. 43, pp. 33238-33243, 2000.

[54] G. A. Gross, T. Imamura, C. Luedke et al., "Opposing actions of prostaglandins and oxytocin determine the onset of murine labor," Proceedings of the National Academy of Sciences of the United States of America, vol. 95, no. 20, pp. 11875-11879, 1998.

[55] K. Nishimori, L. J. Young, Q. Guo, Z. Wang, T. R. Insel, and M. M. Matzuk, "Oxytocin is required for nursing but is not essential for parturition or reproductive behavior," Proceedings of the National Academy of Sciences of the United States of America, vol. 93, no. 21, pp. 11699-11704, 1996.
[56] T. Rogi, M. Tsujimoto, H. Nakazato, S. Mizutani, and Y. Tomoda, "Human placental leucine aminopeptidase/ oxytocinase: a new member of type II membrane-spanning zinc metallopeptidase family," Journal of Biological Chemistry, vol. 271, no. 1, pp. 56-61, 1996.

[57] S. R. Keller, H. M. Scott, C. C. Mastick, R. Aebersold, and G. E. Lienhard, "Cloning and characterization of a novel insulinregulated membrane aminopeptidase from Glut4 vesicles," Journal of Biological Chemistry, vol. 270, no. 40, pp. 2361223618, 1995.

[58] S. R. Keller, A. C. Davis, and K. B. Clairmont, "Mice deficient in the insulin-regulated membrane aminopeptidase show substantial decreases in glucose transporter GLUT4 levels but maintain normal glucose homeostasis," Journal of Biological Chemistry, vol. 277, no. 20, pp. 17677-17686, 2002.

[59] M. G. Wallis, M. F. Lankford, and S. R. Keller, "Vasopressin is a physiological substrate for the insulin-regulated aminopeptidase IRAP," American Journal of Physiology, vol. 293, no. 4, pp. E1092-E1102, 2007.

[60] M. Ishii, A. Hattori, Y. Numaguchi et al., "The effect of recombinant aminopeptidase A on hypertension in spontaneously hypertensive rats: its effect in comparison with candesartan," Hormone and Metabolic Research, vol. 40, no. 12, pp. 887-891, 2008.

[61] S. Mizutani, M. Furuhashi, H. Imaizumi, Y. Ito, O. Kurauchi, and Y. Tomoda, "Effects of human placental aminopeptidases in spontaneously hypertensive rats," Medical Science Research, vol. 15, pp. 1203-1204, 1987.

[62] L. Song and D. P. Healy, "Kidney aminopeptidase A and hypertension, part II: effects of angiotensin II," Hypertension, vol. 33, no. 2, pp. 746-752, 1999.

[63] Y. Hariyama, A. Itakura, M. Okamura et al., "Placental aminopeptidase A as a possible barrier of angiotensin II between mother and fetus," Placenta, vol. 21, no. 7, pp. 621627, 2002.

[64] K. Ino, C. Uehara, F. Kikkawa et al., "Enhancement of aminopeptidase A expression during Angiotensin II-induced choriocarcinoma cell proliferation through AT1 receptor involving protein kinase C- and mitogen-activated protein kinase-dependent signaling pathway," Journal of Clinical Endocrinology and Metabolism, vol. 88, no. 8, pp. 3973-3982, 2003.

[65] G. Vazeux, X. Iturrioz, P. Corvol, and C. Llorens-Cortes, "A glutamate residue contributes to the exopeptidase specificity in aminopeptidase A," Biochemical Journal, vol. 334, no. 2, pp. 407-413, 1998.

[66] K. Okamoto and K. Aoki, "Development of a strain of spontaneously hypertensive rats," Japanese Circulation Journal, vol. 27, no. 6, pp. 282-293, 1963.

[67] Y. Nakashima, Y. Ohno, A. Itakura et al., "Possible involvement of aminopeptidase A in hypertension in spontaneously hypertensive rats (SHRs) and change of refractoriness in response to angiotensin II in pregnant SHRs," Journal of Hypertension, vol. 20, no. 11, pp. 2233-2238, 2002.

[68] A. G. Kieback, H. Iven, K. Stolzenburg, and G. Baumann, "Saterinone, dobutamine, and sodium nitroprusside: comparison of cardiovascular profiles in patients with congestive heart failure," Journal of Cardiovascular Pharmacology, vol. 32, no. 4, pp. 629-636, 1998.

[69] N. D. Binder and J. J. Faber, "Effects of captopril on blood pressure, placental blood flow and uterine oxygen consumption in pregnant rabbits," Journal of Pharmacology and Experimental Therapeutics, vol. 260, no. 1, pp. 294-299, 1992. 
[70] Y. Murata, Y. Ohno, A. Itakura et al., "Bestatin results in pathophysiological changes similar to preeclampsia in rats via induction of placental apoptosis," Hormone and Metabolic Research, vol. 35, no. 6, pp. 343-348, 2003.

[71] R. L. Davisson, D. S. Hoffmann, G. M. Butz et al., "Discovery of a spontaneous genetic mouse model of preeclampsia," Hypertension, vol. 39, no. 2, pp. 337-342, 2002.

[72] S. E. Maynard, J.-Y. Min, J. Merchan et al., "Excess placental soluble fms-like tyrosine kinase 1 (sFlt1) may contribute to endothelial dysfunction hypertension, and proteinuria in preeclampsia," Journal of Clinical Investigation, vol. 111, no. 5, pp. 649-658, 2003.

[73] M. Furuhashi, S. Mizutani, O. Kurachi, M. Kasugai, and Y. Tomoda, "Effects of bestatin on intrauterine growth of rat fetuses," Hormone and Metabolic Research, vol. 21, no. 7, pp. 366-368, 1988.

[74] A. Quan, "Fetopathy associated with exposure to angiotensin converting enzyme inhibitors and angiotensin receptor antagonists," Early Human Development, vol. 82, no. 1, pp. 23-28, 2006.

[75] M. E. Bowen, W. A. Ray, P. G. Arbogast, H. Ding, and W. O. Cooper, "Increasing exposure to angiotensin-converting enzyme inhibitors in pregnancy," American Journal of Obstetrics and Gynecology, vol. 198, no. 3, pp. e1-e5, 2008.

[76] M. Ishii, K. Naruse, A. Hattori et al., "Oxytocin hypersensitivity in pregnant P-LAP deficient mice," Life Sciences, vol. 84, no. 19-20, pp. 668-672, 2009.

[77] T. Imamura, C. E. Luedke, S. K. Vogt, and L. J. Muglia, "Oxytocin modulates the onset of murine parturition by competing ovarian and uterine effects," American Journal of Physiology, vol. 279, no. 3, pp. R1061-R1067, 2000.

[78] T. Engstrøm, P. Bratholm, H. Vilhardt, and N. J. Christensen, "Effect of oxytocin receptor and $\beta 2$-adrenoceptor blockade on myometrial oxytocin receptors in parturient rats," Biology of Reproduction, vol. 60, no. 2, pp. 322-329, 1999.

[79] A. Reversi, V. Rimoldi, T. Marrocco et al., "The oxytocin receptor antagonist atosiban inhibits cell growth via a "biased agonist" mechanism," Journal of Biological Chemistry, vol. 280, no. 16, pp. 16311-16318, 2005.

[80] S. Mizutani, O. Kurauchi, Y. Ito, O. Narita, and Y. Tomoda, "Positive effect of estradiol and progesterone in severe preeclampsia," Experimental and Clinical Endocrinology, vol. 92, no. 2, pp. 161-170, 1988.

[81] G. V. Smith and O. W. Smith, "Estrogen and progestin metabolism in pregnancy," Journal of Clinical Endocrinology, vol. 1, pp. 477-484, 1941.

[82] Y. Katsumata, S. Nomura, K. Ino et al., "Progesterone stimulates the expression of aminopeptidase $\mathrm{A} /$ angiotensinase in human choriocarcinoma cells," Placenta, vol. 22, no. 10, pp. 831-836, 2001.

[83] S. Matsuura, A. Itakura, Y. Ohno et al., "Effects of estradiol administration on feto-placental growth in rat," Early Human Development, vol. 77, no. 1-2, pp. 47-56, 2004.

[84] D. J. P. Barker, "Maternal nutrition, fetal nutrition, and disease in later life," Nutrition, vol. 13, no. 9, pp. 652-655, 1997. 


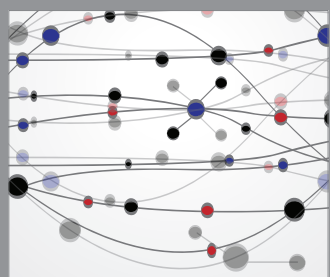

The Scientific World Journal
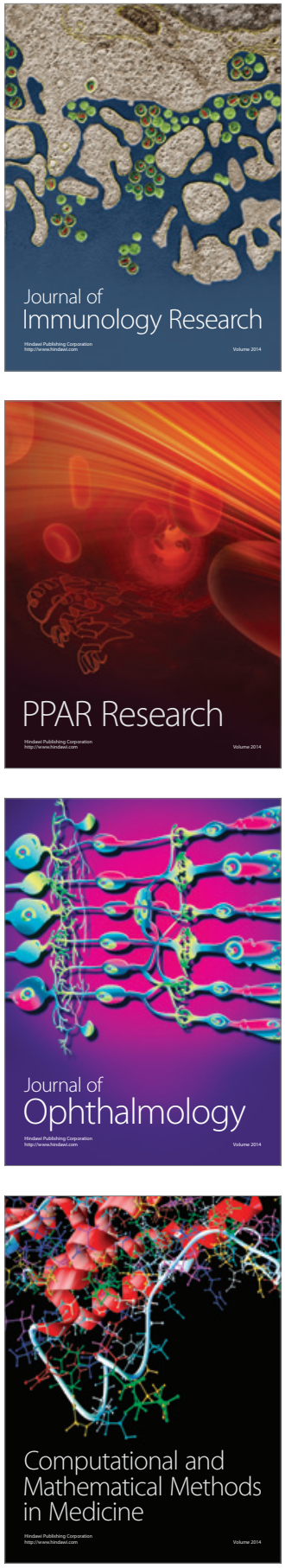

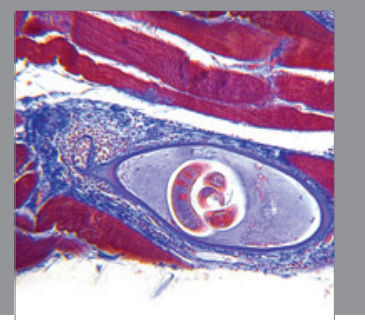

Gastroenterology

Research and Practice
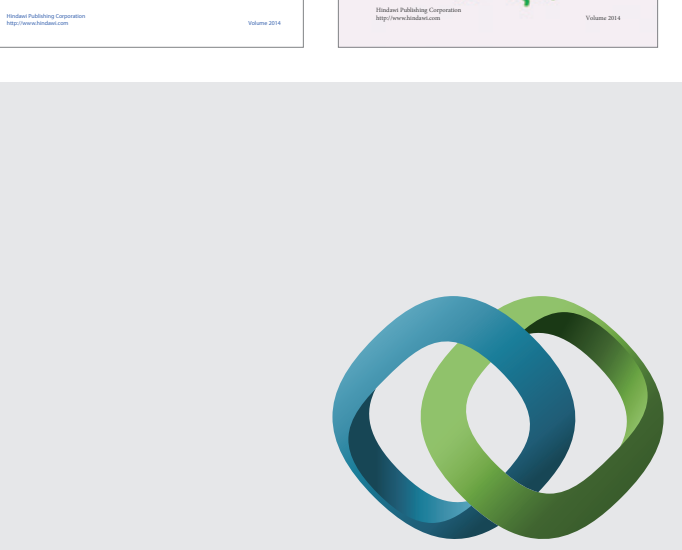

\section{Hindawi}

Submit your manuscripts at

http://www.hindawi.com
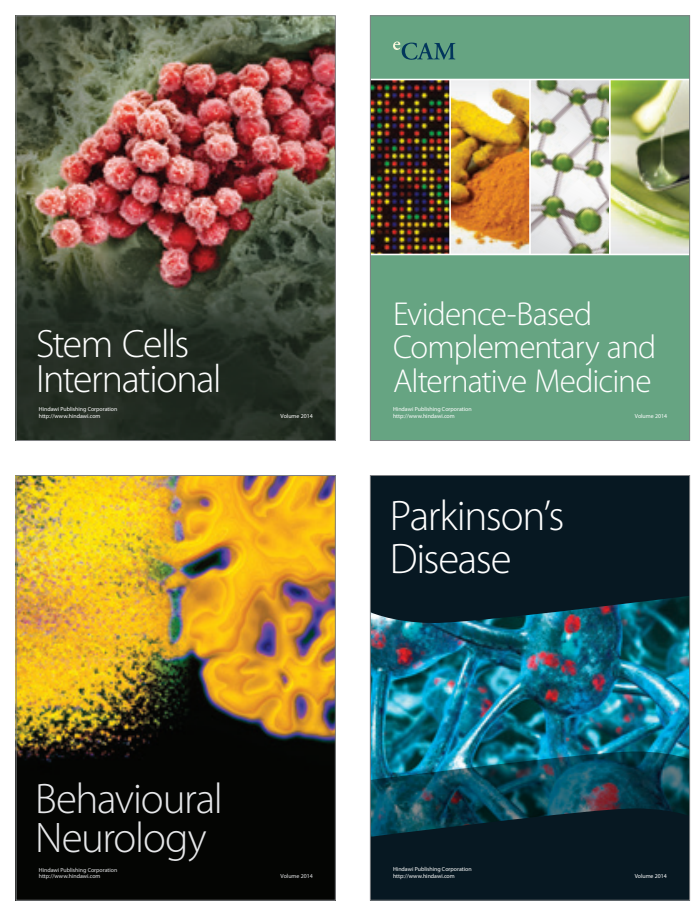

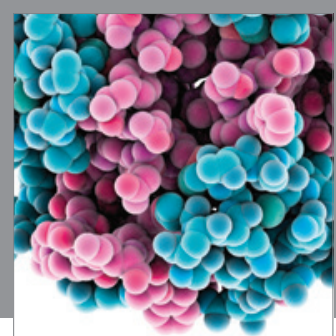

Journal of
Diabetes Research

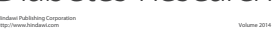

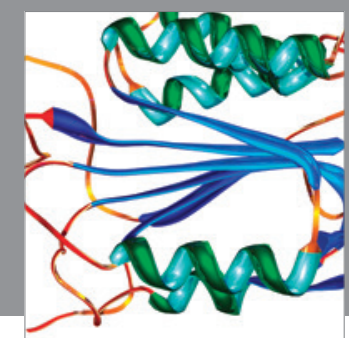

Disease Markers
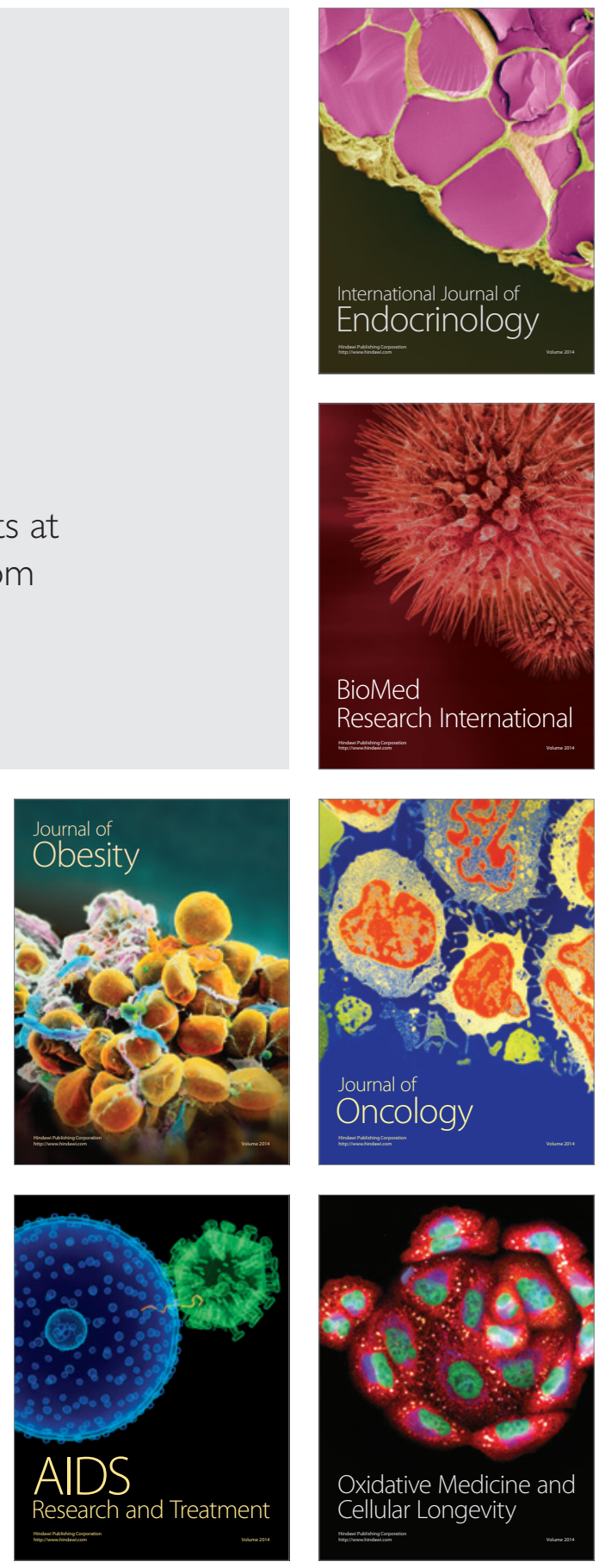